\title{
Actors, decision-making, and institutions in quantitative system modelling
}

\author{
Enrica De Cian $^{\mathrm{a}, \mathrm{c}, \mathrm{d}}$, Shouro Dasgupta ${ }^{\mathrm{b}, \mathrm{c}, \mathrm{d}, *}$, Andries F. Hof ${ }^{\mathrm{e}, \mathrm{f}}$, Mariësse A.E. van Sluisveld ${ }^{\mathrm{e}, \mathrm{f}}$, \\ Jonathan Köhler ${ }^{g}$, Benjamin Pfluger ${ }^{g}$, Detlef P. van Vuuren ${ }^{\text {e,f }}$ \\ a Department of Economics, Università Ca' Foscari Venezia, Italy \\ b Department of Environmental Sciences, Informatics and Statistics, Università Ca' Foscari Venezia, Italy \\ ${ }^{\mathrm{c}}$ RFF-CMCC European Institute on Economics and the Environment, Italy \\ ${ }^{\mathrm{d}}$ Centro Euro-Mediterraneo sui Cambiamenti Climatici (CMCC), Italy \\ ${ }^{\mathrm{e}}$ Netherlands Environmental Assessment Agency (PBL), Netherlands \\ ${ }^{\mathrm{f}}$ Copernicus Institute of Sustainable Development, Utrecht University, Netherlands \\ ${ }^{\mathrm{g}}$ Fraunhofer Institute for Systems and Innovation Research ISI, Germany
}

\section{A R T I C L E I N F O}

\section{JEL classification:}

C63

$\mathrm{O} 10$

P16

Q00

Q4

Q5

\section{Keywords:}

Modelling

Transition pathways

Scenarios

Actors

Institutions

Governance

$\mathrm{ABM}$

IAM

\begin{abstract}
A B S T R A C T
Increasing realism in quantitative system modelling with respect to the representation of actors, decisionmaking, and institutions is critical to better understand the transition towards a low-carbon sustainable society. Yet, studies using quantitative system models, which have become a key analytical tool to support sustainability and decarbonization policies, focus on outcomes, therefore overlooking the dynamics of the drivers of change. We explore opportunities that arise from a deeper engagement of quantitative systems modelling with social science. We argue that several opportunities for enriching the realism in model-based scenario analysis can arise through model refinements oriented towards a more detailed approach in terms of actor heterogeneity, as well as through integration across different analytical and disciplinary approaches. Several opportunities that do not require major changes in model structure are ready to be seized. Promising ones include combining different types of models and enriching model-based scenarios with evidence from applied economics and transition studies.
\end{abstract}

\section{Introduction}

Model-based scenario analysis has become a key analytical approach to explore low-carbon transitions in line with pre-defined future global environmental and sustainability goals. An important reason for this is that models, which in this paper always refers to quantitative systems models, can provide insights into interactions between sectors, different sustainability goals, linkages across topics, scales, regions, as well as into indirect economic linkages (van Vuuren and Kok, 2012). The approach makes it possible to examine the relationship between near-term decisions and long-term trends and objectives by accounting for relevant (environmental, economic, energy) system inertia. Modelbased scenarios have provided support to high-level decision-making in the fields of environment, sustainable development, and transitions towards low-carbon economies. For example, the conclusions of the Fourth Assessment Report (AR4) by the Intergovernmental Panel on Climate Change (IPCC) provided the evidence for the European Union to adopt a greenhouse gas emission reduction target of $80 \%-95 \%$ in 2050 compared to 1990 levels to remain aligned with the $2{ }^{\circ} \mathrm{C}$ global climate objective $^{1}$ (Gupta et al., 2007; IPCC, 2007). Model-based scenarios have also been helpful in informing negotiators and heads of state during the establishment of the Paris Climate Agreement ${ }^{2}$ (UNFCCC, 2015).

The increasing focus on the implementation of low-carbon policies and the considered transition dynamics towards achieving long-term objectives requires greater attention to how these changes will take

\footnotetext{
* Corresponding author at: Department of Environmental Sciences, Informatics and Statistics, Università Ca' Foscari Venezia, Italy.

E-mail address: shouro.dasgupta@cmcc.it (S. Dasgupta).

${ }^{1}$ Council of the European Union, 2009. Brussels European Council 29/30. October 2009 - Presidency conclusions, https://www.consilium.europa.eu/uedocs/cms_ data/docs/pressdata/en/ec/110889.pdf.

${ }^{2}$ G7, 2015. Leaders' declaration G7 summit - Think Ahead, Act Together, 7-8 June 2015, Schloss Elmau.
} 
place and to ways to accelerate them. The fundamental transformation of consumption and production systems required by deep decarbonization strategies involves a reconfiguration of technologies, infrastructures, and industries but computational models often overlook other important elements such as the implicated change in business models, dominant ideas, cultural discourses, and institutions, as they are inherently restricted to quantifiable techno-economic relationships. As a result, decarbonization strategies are characterized by elements that have been empirically quantified or estimated, such as future technological performance or costs. Elements that go beyond the techno-economic realm, such as actors, individual decision-making, and institutions that involve more than one state of being (such as co-existing ideals, hence no clear solid trend to extrapolate) are difficult to represent.

Model-based analysis has already shifted from first-best transition pathways (fully oriented towards cost-optimality under perfect conditions, Clarke et al., 2014) to second-best transition pathways (exploring socio-political and innovative limitations, e.g. Kriegler et al., 2013a, 2013b; Staub-Kaminski et al., 2013; Tavoni et al., 2013; Kriegler et al., 2015; Riahi et al., 2015). However, given the rather techno-economic orientation of this type of assessment, contextual factors such as institutions, actors, and power structures, all of which influence the behavior both at the aggregate and individual levels, remain underexplored as it remains difficult to represent these factors mathematically.

The need to improve the representation of the behavioral and institutional components in models is being explored by a growing number of researches. ${ }^{3}$ In this paper, we investigate how model-based scenarios can be enriched by looking into the role of actors, decisionmaking, and institutions in different model types, and outline possible connections that could lead to a deeper engagement with social sciences (Victor, 2015). We discuss how opportunities to improve behavioral realism, the degree of heterogeneity, and the representation of institutional and governance factors can arise through collaboration among scientists from different disciplines such as modelers, sociologists, empirical economists, and political scientists. We illustrate the potential of this collaboration by focusing on three types of quantitative system models widely used in scenario transition studies; Integrated Assessment Models (IAMs), Energy System Models (ESM), and AgentBased Models (ABMs).

IAMs provide simplified representations of both the human and natural systems. With regard to the human systems, most IAMs are outcome-oriented, i.e. they provide insights into systemic change and focus on the consequences of exogenously specified policies, with limited attention to the processes and the social interactions leading to outcomes (Hofman et al., 2004). The representation of non-technological factors, such as interactions among actors and interest groups, political economy factors and institutions, remains therefore stylized, as they are difficult to capture in the mathematical equations of the models (van Vuuren and Kok, 2012), often addressed through detailed scenario narratives (see e.g. SRES (Nakicenovic et al., 2003) and SSPs (O'Neill et al., 2010, 2015)). The representation of governance and institutions is limited to the actions of the state or the government, for which regulations and policies are generally represented as an exogenous shock/disruption implemented by a social planner. Some IAMs have dedicated more attention to the role of different actors and actor heterogeneity, as reviewed by Krey (2014) and Wilson et al. (2014). Examples of heterogeneities included in models are urban-rural divide, income distribution, consumer groups, and household composition (Ekholm et al., 2010; Eom et al., 2012; Krey et al., 2012; McCollum et al., 2017; Melnikov et al., 2012; Melnikov et al., 2017; O'Neill et al.,

\footnotetext{
${ }^{3}$ See for example COBHAM (http://cordis.europa.eu/project/rcn/191138_ en.html), ADVANCE (http://www.fp7-advance.eu/ and Wilson et al., 2014), WholeSEM http://www.wholesem.ac.uk/).
}

2012; van Ruijven et al., 2011).

Energy System Models share many of the characteristics and limitations of IAMs. They are also outcome-oriented, despite the higher level of technological detail in the energy sector. These models have a stronger focus on detailed technological changes of the energy sector or of a part of it (e.g. electricity system), while the macroeconomic system is modeled exogenously, thus disregarding potential inter-sectoral feedbacks. Demand is usually an exogenous input to the model, while market prices are calculated endogenously. Decisions are represented by actions of one or more representative social planners, while the representation of institutions is limited and indirect.

A different approach is offered by ABMs, which are dedicated models to analyze the decision-making of different actors. They provide an explicit representation of agent heterogeneity and of interactions across agents (Epstein and Axtell, 1996). ABMs are designed to capture the agents' perception of the relevant aspects of their environment and their decision-making according to their rationality. They often describe the interactions among different actors that operate according to prescribed behavioral rules and can capture emergent phenomena (Farmer et al., 2015). Most ABM applications focus on specific regions or depict only parts of the energy system, e.g., investments in renewable electricity, improvements in buildings, or the transportation sector.

The differences in the representation of actors, decision-making, and institutions between IAMs, ESMs, and ABMs arise from their different objectives. IAMs are intended to illustrate long-term, global emissions, interactions and implications across natural and human systems. ESMs are intended to provide more technologically detailed information on the energy system specifically. ABMs can illustrate possible pathways of change at the level of individual decision-making, taking into account the behavioral implications of agents' heuristics and interactions with other agents. IAMs and ESMs are cost-oriented models as the decisions in these models are based on choices regarding relative costs of technologies (e.g. capital, operation and maintenance), while decisions in ABMs depend on a richer diversity of technological and non-technological factors.

The remainder of the paper is organized as follows. Section 2 provides a detailed discussion on the models' assumptions regarding actors, decision-making, and institutions by drawing on examples of the three streams of models; Section 3 discusses opportunities for model improvements; and Section 4 concludes.

\section{Representations of actors, decision-making, and institutions in models}

This section describes the characterization of actors, their decisionmaking, and institutions in IAMs, ESMs, and ABMs. We build on the experience of the authors with four specific models; two IAMs - IMAGE (Stehfest et al., 2014) and WITCH (Emmerling et al., 2016), one Energy System Model - Enertile ${ }^{4}$ and one ABM - MATISSE-KK (Köhler et al., 2009, 2018). Section 2.1 discusses the representation of actors and decision-making, while Section 2.2 focuses on the representation of institutions.

\subsection{Actors and decision-making}

A first important element that varies across models is the decision making and the decision makers. Table 1 summarizes the main features regarding the representation of actors, decision variables, and decisionmaking in models. We can distinguish between optimization/equilibrium (implicit social planner with limited or perfect foresight) and simulation (recursive decision-making based on a representative agent and current relative costs differences for concurrent services and technologies) models.

\footnotetext{
${ }^{4}$ www.enertile.eu
} 
Table 1

Representation of actors and decision-making across models.

Source: Authors' compilation.

\begin{tabular}{|c|c|c|c|c|}
\hline & $\begin{array}{l}\text { IMAGE } \\
\text { Simulation IAM }\end{array}$ & $\begin{array}{l}\text { WITCH } \\
\text { Optimization IAM }\end{array}$ & $\begin{array}{l}\text { Enertile } \\
\text { Optimization energy system } \\
\text { model }\end{array}$ & $\begin{array}{l}\text { MATISSE-KK } \\
\text { Agent-based model }\end{array}$ \\
\hline Actors & $\begin{array}{l}\text { Implicitly represented, decisions are } \\
\text { described for individual markets. } \\
\text { Differentiation between urban and } \\
\text { rural households. }\end{array}$ & $\begin{array}{l}\text { Aggregate regional social } \\
\text { planners }\end{array}$ & $\begin{array}{l}\text { Aggregate European social } \\
\text { planner }\end{array}$ & $\begin{array}{l}\text { Agents are modeled explicitly, } \\
\text { differentiating between consumers, niches, } \\
\text { regime }\end{array}$ \\
\hline Decision-making & $\begin{array}{l}\text { Constrained cost minimization without } \\
\text { perfect foresight }\end{array}$ & $\begin{array}{l}\text { Constrained welfare } \\
\text { maximization with perfect } \\
\text { foresight }\end{array}$ & $\begin{array}{l}\text { Constrained cost minimization } \\
\text { with perfect foresight }\end{array}$ & $\begin{array}{l}\text { Niches: change the technology-lifestyle } \\
\text { characteristics to survive } \\
\text { Regimes: maximize market share } \\
\text { Consumers: adopt the regime or a niche } \\
\text { lifestyle/technology }\end{array}$ \\
\hline Decision variables & Investments and dispatch & Investments and dispatch & Investments and dispatch & $\begin{array}{l}\text { Niche and Regime: Direction of } \\
\text { technological change } \\
\text { Consumer: Technology -lifestyles adoption }\end{array}$ \\
\hline
\end{tabular}

In WITCH and Enertile, decisions are taken by one or more social planners, who make a top-down decision between a broad set of investment choices and consumption. In WITCH, regional social planners maximize a welfare function and choose the intertemporal resource allocation between consumption and investments. In Enertile, a European social planner minimizes total system costs across technologies and across EU countries. As both WITCH and Enertile are full optimization models with perfect foresight, they have full future knowledge and optimize investment decisions over the entire time horizon. In WITCH, investments decisions are based on country-specific returns on investment (endogenous in the model), which in turn are affected by exogenously specified capital and operation and maintenance costs. WITCH builds on neoclassical economic theory, viewing agents as rational with a clear objective achieved through optimization. Both WITCH and Enertile rely on rational choice and optimizing decisionmaking rules in the form of either welfare maximization or cost minimization. Simulation models such as IMAGE optimize investment decisions year-by-year in a recursive-dynamic way. Decisions regarding services and technologies are made based on the relative costs of an ensemble of choices (consisting out of explicit (e.g. capital, Operation and Maintenance (O\&M)), and implicit (e.g. preferences) cost factors), which are specified per region and programmed to develop over time under the effect of various exogenous and endogenous time-based factors (e.g. carbon tax) and other interdependencies (e.g. economies of scale). Using a multinomial logit formulation, the option with the relatively lowest costs will acquire the largest market share.

In both techno-economic modelling styles, the representation of agency is mostly conflated to global or regional governments, rather than individuals making decisions. However, despite such aggregation, a multitude of actors is implicitly assumed responsible for investment decisions (Table 2). Even if the same technology is adopted in different scenarios, the associated actors may differ depending on the assumed

Table 2

Examples of implicit actors in models.

Source: Authors' compilation.

\begin{tabular}{ll}
\hline Factors influencing investment decisions in models & Associated actor \\
\hline Purchasing price & Manufacturers/R\&D \\
Fuel cost & OPEC \\
Preferences & Consumers \\
Capital costs & Investors \\
O\&M costs & Mechanics \\
CO2 tax & Government \\
System integration costs & Energy companies \\
Cost curves & Research institutes \\
Exogenous assumptions & Politics \\
\hline
\end{tabular}

narrative. Investments in solar PV, for instance, can be made by large utilities in the form of large-scale PV or by consumers in the form of small-scale rooftop PV. While Enertile distinguishes between these two technologies, IMAGE and WITCH do not. In case of the latter, one is more dependent on the interpretative capabilities of the modeler to distinguish between the different social causal chains. Even then, this interpretative capacity is bounded by the cost-optimal techno-economic framework of the applied computational model, as outcomes need to be framed in terms of rational, economic behavior, and assumptions of perfect knowledge.

An explicit representation of actors is provided in the MATISSE-KK $\mathrm{ABM}$, which specifies different types of agents characterized by different decision-making processes in the transportation sector. MATISSE-KK is intended to address changes in a society through changes in mobility patterns or lifestyles. These changes are modeled as the decisions of households to keep the current pattern of mobility or to change it. The model incorporates the concepts of niches and the regime in the sense of the Multi-Level Perspective (MLP) on transitions (Köhler et al., 2009). A regime refers to the dominant structure consisting of the dominant culture and practices in a system. The regime in mobility is the conventional internal combustion engine, which the majority uses for most of their mobility needs. Niches refer to individuals or a small group of actors with local practices, which differ from the regime. Consumers choose whether to adopt the regime or a niche lifestyle/technology. A large number of simple agents whose function is to allocate support to the regime or a niche determine the relative strength of the regime and niches.

ABMs such as MATISSE-KK can specify different rules and differentiate among them by type of agents. Consumers make decisions regarding the adoption of the regime or niche technologies based on a set of attributes (practices) including environmental performances (e.g. emissions), technology costs, demand split, Information and Communication Technologies (ICT) use, and the structure of the built environment with regards to provision for the different transport modes. Consumers choose regime or niches technologies/lifestyles based on their preferences. The technologies or lifestyles form niches and a regime, which are also represented as agents in the model. The regime and niches develop over time as technology improves, depending on the support that the technology/lifestyle receives from the consumers.

Despite the differences in disciplinary philosophy between ABMs and the other types of models, the four models reviewed in Table 1 share similarities in terms of a choice variable that is always related to technology adoption. Across all these models, the decision of actors is primarily determined by technological and contextual factors. Technological factors describe the characteristics, costs, and environmental 
Table 3

Different types of institutions.

Source: Scott (1995).

\begin{tabular}{|c|c|c|c|}
\hline & Regulative & Normative & Socio-cognitive \\
\hline Examples & $\begin{array}{l}\text { Formal rules, laws, sanctions, incentive structures, } \\
\text { reward and cost structures, governance systems, power } \\
\text { systems, protocols, standards, procedures }\end{array}$ & $\begin{array}{l}\text { Values, norms, role expectations, } \\
\text { authority systems, duty, codes of } \\
\text { conduct }\end{array}$ & $\begin{array}{l}\text { Priorities, problem agendas, beliefs, bodies of } \\
\text { knowledge (paradigms), models of reality, categories, } \\
\text { classifications, jargon/language, search heuristics }\end{array}$ \\
\hline Basis of compliance & Incentives & Social obligation & Many, including cognition around decision making \\
\hline Mechanisms & Coercive (force, punishments) & $\begin{array}{l}\text { Normative pressure (social sanctions } \\
\text { such as 'shaming') }\end{array}$ & Mimetic, learning, imitation \\
\hline Logic & Instrumentality (creating stability, 'rules of the game') & $\begin{array}{l}\text { Appropriateness, becoming part of } \\
\text { the group ('how we do things') }\end{array}$ & Orthodoxy (shared ideas, concepts) \\
\hline
\end{tabular}

performance of technologies in terms of lifetime, efficiency, learning, and emission performance. Contextual factors include social, behavioral, or regulatory changes such as the implementation of climate policy or technology subsidies. We refer to these regulatory changes as institutions and discuss them in detail in Section 2.2.

\subsection{Institutions}

Contextual factors such as institutions influence the decisionmaking process in models. In models, institutions are often represented through exogenous decision rules describing the decision process of aggregate/representative actors or through exogenous factors influencing the outcome of the decision process. This is a narrow approach, as institutions encompass many aspects of society, despite the different definitions of institutions across disciplines. A broad definition of institutions is provided by Scott (1995), who groups institutions into three large sets; regulative, normative, and socio-cognitive (Table 3). This definition implies that institutional change refers not only to the direct effect of policies and regulations but also to changes in our vision of the world, as well as changes in our normative aspirations and what we consider being good.

The applied economic literature uses a narrower definition of institutions, mostly referring to formal institutions (Acemoglu et al., 2005; Dasgupta and De Cian, 2018). They can be further grouped into legal (e.g. judiciary and legislature), political (e.g. form of government; democracy or autocracy), and economic (e.g. tax-collection agencies) institutions. Legal institutions take the form of legislature, public or state-devised legal institutions, and private legal institutions, while political institutions shape policy decisions by constraining the set of feasible choices of the decision-makers and by creating and enforcing laws and governmental policy making. Economic institutions perform functions such as establishing and protecting property rights, facilitating transactions, permitting economic co-operation, and organization (Acemoglu and Robinson, 2010). A related and to some extent overlapping concept of governance can be broadly defined as the traditions and institutions that determine how authority is exercised in a country (Kaufman et al., 2010) while the World Bank defines governance as the power exercised through a country's institutions. In this context institutions and governance refers to the actions of the state or the government.

Table 4 summarizes the representation of regulatory, normative, and socio-cognitive institutions in different models. Formal regulatory institutions as implemented by national or transnational political organizations are the main type of institutions commonly represented by IAMs and ESMs. The main drivers of change of regulatory institutions are climate policy instruments (e.g. carbon tax and emission trading scheme) and policy targets, which can be sector or technology specific (e.g. a PV subsidy). These types of institutions are quantitatively modeled by describing the long-term climate policy goals, the policy regimes and measures, as well as implementation limits and obstacles (Kriegler et al., 2015).

When implemented, regulations are commonly assumed to be effective at achieving the objective. In both IAMs and ESMs, policies are often represented by a global uniform carbon tax or price applied to all sectors and regions, assuming cost-optimization over sectors, regions, and time (Clarke et al., 2009Kriegler et al., 2013b) with the main goal of providing insight into cost-efficient reduction strategies. Once the policy is adopted, its effectiveness is generally assumed to be unaffected by the institutional framework, as models assume the same governance style and power structures over centuries (top-down steering).

Even though models focus on the effects of regulations and policy prescriptions, contextual factors and normative dimensions (such as beliefs, mindsets, preferences, normative aspirations, and the notion of what is good) are also implicitly included in model assumptions and parameter choices. For example, in optimizing macroeconomic models, normative assumptions are embedded in the welfare function. The welfare function is used for intertemporal optimization, a process to evaluate the trade-off between current and future consumption. The representative agent of the model, a benevolent national or supranational government, decides on the allocation of resources between consumptions and savings. Similar to individual decisions on consumption and savings, this decision depends on the implemented subjective degree of risk aversion and the importance given to future consumption. A similar reasoning applies to the mechanisms that choose between investing in clean energy to reduce the future damages from climate change or to achieve a long-term mitigation target. Models specify parameters affecting discounting of the future. These include the pure rate of time preference describing the weight of future generations in intertemporal welfare considerations and the intertemporal elasticity of substitution describing the willingness to smooth consumption over time. Lowering the discount rate in models places more weight on the future relative to current costs and benefits and therefore favors technologies with high initial investment such as wind power, which after the initial investments are carried out, delivers power at almost zero marginal cost.

Socio-cognitive institutions refer to priorities, problem agendas, and beliefs, and can be represented in IAMs and ESMs implicitly by differentiating preferences for energy technologies by changing their relative costs. For example, societal preferences for energy technologies can be represented implicitly through ad-hoc adjustments in costs, or exogenous shifts imposed by modelers (e.g. phasing out of nuclear power, opposition to CCS, and services versus ownership). For example, IMAGE includes a premium factor (subsidy, tax, or preference for a certain technology) to modify (investment) costs and to calibrate against historical data. Indeed, according to historical data, it is evident that some technologies have a higher market share than can be explained by costs alone. For instance, many consumers prefer an electric vehicle above a gasoline vehicle even if the costs of electric vehicles over the whole life time are (still) higher. The acceptance of households as power suppliers into the grid can also be represented by the inclusion of consumer power producers. Changes in norms about energy and mobility behavior (e.g. lowering indoor temperatures to save on energy use or a driving style that minimizes energy use rather than driving as fast as possible) can be modeled by modifying energy and fuel demand 
functions for the relevant technologies. This can be done for a representative consumer/producer and for a distribution of consumer and producer decision-making types.

ABMs can explicitly control for normative institutions, such as lifestyle expectations of individuals in energy and mobility systems, as well as for markets and socio-cognitive institutions. For example, in the MATISSE-KK model consumers have different weights simulating different preferences for mobility lifestyles, as well as for climate issues. The MATISSE model was calibrated on transport modal split for the UK and the Netherlands using 2015 data from Eurostat (Köhler et al., 2018). The authors explain how the behavioral parameters were calibrated using the results of the transitions case studies of the UK and the Netherlands. These identified the alternative mobility lifestyles to be studied in addition to the regime: hybrid electric cars, battery electric cars, hydrogen fuel cell cars, car sharing, public transport, cycling and walking.

Overall, we can conclude that the representation of institutions in models is stylized and implicit. ABMs offer a richer framework for characterizing institutional heterogeneity, though still mostly exogenously as specified by the modeler. While institutions affect the decision process in models, actors cannot affect the broader institutional setting. Although the elements of models can be associated with different assumptions on institutions, modelers usually specify them exogenously.

\section{Improving the representation of actors, decision-making, and institutions in models}

As discussed in Section 2, models rely on mathematical equations, variables, and parameters to quantitatively describe contextual factors that influence models' choices in addition to price and technological factors. When establishing different climate policy scenarios, models generally vary the regulatory or technological dimension (Kriegler et al., 2013a, 2013b, 2014, 2015; Tavoni et al., 2013) but social and behavioral factors are often left unchanged. For example, stabilization scenarios aimed at achieving a predefined level of greenhouse gases concentration are often characterized by technological substitution without requiring major reconfiguration in the underlying societal configuration of actors. This section outlines possible routes of improvements in the modelling of actors, their decision-making, and institutions. Section 3.1 discusses the opportunities for enhancing realism with respect to actors and decision-making representation by (i) codesigning use of transition narratives, (ii) improving actor heterogeneity, (iii) linking ABMs and IAMs, and (iv) linking initiative-based learning and models. Section 3.2 discusses whether the existing framework of IAMs, ESMs, and ABMs can attend to the institutional dimensions outlined in Table 3 by (i) linking the applied economic literature and modelling or (ii) performing a comparative analysis of transition pathways.

\subsection{Actors and decision-making}

\subsubsection{Co-designing transition narratives}

One way to strengthen the representation of actors and decisionsmaking in quantitative modelling is to complement the quantitative material with qualitative perspective. Several methods have been applied in literature to include qualitative aspects into quantitative modelling, which all comprise of embedding more contextual detail into the transition narrative. This can be done in a mono-disciplinary setting (e.g. by the modelling community itself, such as found in Nakicenovic et al., 2000; O'Neill et al., 2014) or in an interdisciplinary setting (e.g. via comprehensive co-creation structures with stakeholders, see Voinov and Bousquet, 2010; Voinov et al., 2014) or disciplinary bridging of (empirical) knowledge bases (Turnheim et al., 2015).

In the latter case, soft forms of integrating quantitative system modelling with socio-technical transition studies have been proposed in 
the literature (Turnheim et al., 2015), ${ }^{5}$ suggesting it can deliver heuristic insights on long-term sustainability transition scenarios. As demonstrated in van Sluisveld et al. (this issue), quantitative modelling can be aligned to MLP, although other theoretic frameworks that can provide insights on social actor behavior exist (e.g. Markard et al., 2012). MLP approaches analyze the multiple dimensions of change, including a broad range of technological, economic, political, and socio-cultural aspects at different levels and temporalities. They can be used to develop typologies as theoretical constructs and analytical devices to make sense of transitions (Turnheim et al., 2015). These typologies of transition narratives, often based on case studies (Geels and Schot, 2007), can be used to inform and characterize pathways from quantitative system models. In that sense, MLP provides a more (limited) forward-looking perspective allowing modelers to include a more 'calibrated narrative' to emerging future change than currently adopted in the long-run empirical trends on growth and diffusion.

Examples illustrating the alignment between MLP and quantitative models have recently started to be published. In the mobility domain, actor heterogeneity can be expressed by reconsidering the preferences for modes and vehicles used to meet the total travel demand. Some degree of behavioral change can be implemented by tweaking specific parameters such as vehicle occupancy rates, time, and monetary budgets for travel and preference factors for certain modes or vehicle types. Köhler et al. (2018), use evidence from transitions case studies of the UK and the Netherlands to model actor heterogeneity. Adoption of different mobility lifestyles depend not only on preferences towards less $\mathrm{CO}_{2}$ emissions but also on consumers' preferences towards mixed use of urban structures and a shift away from private conventional car ownership. As described in van Sluiced et al. (this issue), MLP insights have provided indication of more emergent (short-term) directions of change across various economic sectors to the IMAGE model. By heeding to MLP-based insights, the model shows to boost electricity-based technological substitutes more than compared to only techno-economic considerations.

\subsubsection{Increasing actor heterogeneity}

In order to increase the resolution of the social sphere on lowcarbon transitions, one can also create more explicit representations of either (i) processes or (ii) representative agents in quantitative computational models. A more detailed model structure would offer more levers for integrating inputs and insights from other disciplines, providing further opportunities to address social actor behavior within the broader scope of global system change modelling (Li, 2017). Table 5 illustrates how IMAGE, due to its richer characterization of the household energy demand and transport sector, is able to implement a number of interventions to simulate social and behavioral change, such as smaller dwelling sizes, reduced ownership of appliances, and a more efficient use of household appliances (van Sluisveld et al., 2016; van Sluisveld et al., 2018).

Actor heterogeneity can be accounted for by making regional and demographic elements explicit, such as differentiating between urban and rural areas, income classes, and cultural variation in energy demand. The decision mechanisms, however, remain broadly driven by techno-economic considerations without endogenously incorporating socio-technical aspects and influences. Hence, another line of development is to make actor behavior more internally dynamic and conditional to non-economic factors. For instance, recent developments in the IAM community have focused on expanding the representations of actors by explicating several types of consumer groups in the transport sector (e.g. McCollum et al., 2017). Specific attitudes towards technology adoption (e.g. early adopter, laggard) are implemented by

\footnotetext{
${ }^{5}$ See van Sluisveld et al. (2018) for a detailed description of this form of integration, specifically, MLP theoretical framework (Geels, 2002Geels and Schot, 2007).
}

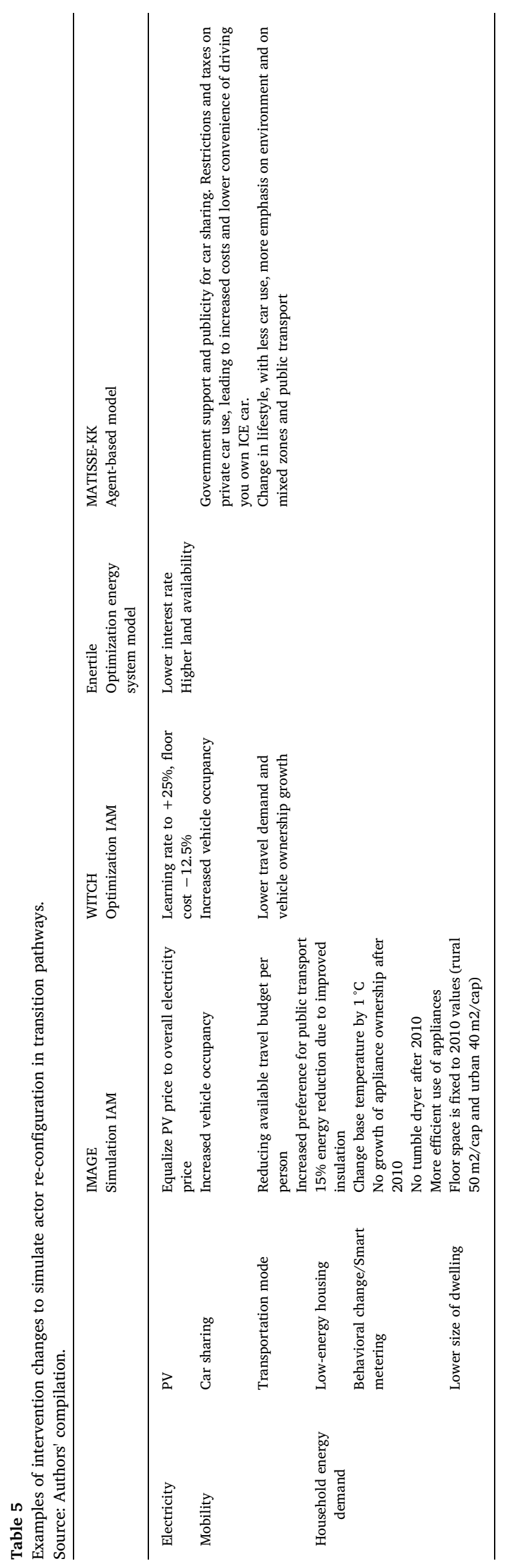


monetizing qualitative concepts (such as preference, social influence, and risk aversion) and including these as factors in the decision-making mechanisms of the computational models.

ABMs such as MATISSE-KK are also more suitable to differentiate between types of agents. MATISSE-KK indeed has four groups of actors in relation to transportation choices, namely conventional car drivers, green car drivers, public transport users, and cyclists or pedestrians. These groups have different preferences that reflect the characteristics of the dominant technologies in each of these mobility lifestyles. A critical limitation is that the agents are still individual decisionmakers, although there is strong evidence that individual consumers are influenced by the surrounding culture and social contacts (Köhler, 2006; Shelley, 2012). While the MATISSE-KK model does allow changes in preferences over time, as a representation of changes in mobility culture in the society to reflect situations such as an increasing priority of emissions reduction, the model could be extended to include direct interactions among the individual consumer agents.

Empirical evidence from microeconomic studies could be used to introduce increased heterogeneity in preferences and behaviors across sectors and regions. Table 5 illustrates examples of model parameters that offer a lever to integrate evidence from other disciplines. There is indeed a broad empirical literature on microeconomic behaviors related to technology adoption, highlighting the great variety of technical and non-technical determinants of technology investments and adoption that could be used for this purpose. For opportunities in this direction see (Mundaca et al., 2010; Wilson et al., 2014; Wilson et al., 2018).

\subsubsection{ABMs and IAMs}

In theory, it is possible to develop Agent-Based IAMs. One possibility would be to have two different types of agents instead of a single representative agent or a centralized social welfare maximizer. However, this would represent a change in the underlying theory, which would require a reconsideration of other principles of the model as well. An alternative approach is to use the results of ABMs to inform the calibration of the IAMs and the other way around. ABMs could provide insights on how the travelled per capita kilometers are spend in a higher resolution setting (e.g. working from home, tele-calling to enrich the set of solutions for society that go beyond technological substitutions. This could be achieved by defining these lifestyle solutions and their emissions and price characteristics as part of the choice sets in the IAM. Yet, IAMs would deliver more aggregated outcomes, which would then need to be unpacked in plausible storylines. In the field of passenger transport, an example of such a lifestyle change could entail a change from personal automobiles to public intermodal transportation. This could be achieved by changes in the preference structure of the consumers and by changes in the generalized costs of the different modes. In the field of energy, this could involve a shift from buying energy as a consumer to becoming a combined supplier and consumer, with an automated energy management system optimizing a combination of decentralized generation, energy storage, and energy purchase - depending on real time current prices and costs. However, this is a rather unexploited field of study and would require more applications and experience.

\subsubsection{Initiative-based learning and models}

The evidence from Initiative Based Learning (IBL) can be used to enrich the representation of actor behavior and decision-making in models regarding the process of technological diffusion and learning. IBL is a qualitative approach that uses case study analysis to examine the mechanisms and dynamics in concrete projects and local initiatives involving a wide range of societal actors such as citizens, businesses, civil society organizations, and (local) government. It reveals the emerging properties in processes of system change ignored by approaches such as quantitative system models and informs us about the configuration of actors and motives that lead to successful solutions that favor innovation (Turnheim et al., 2015). IBL focuses on entangled social dynamics in local transition initiatives and pays less attention to the broader and long-term perspectives on transition dynamics. IBL provides interesting insights into forms of learning that remain unobservable in quantitative system models. In this approach, learning focuses on social learning, namely the processes and interaction among actors that determine the success or failure of a given initiative, including organizational and cultural aspects.

The evidence from IBL could also be used to offer a more realistic representation of learning dynamics in models, for example, in the context of renewable technologies. While IBL highlights mechanisms involving the interaction among agents and actors, models emphasize the learning mechanisms related to the process of production and use of specific technologies (learning-by-doing). Quantitative system models rely on empirical evidence to parameterize the learning curves describing learning-by-doing dynamics, but the empirical estimates (i) span a very broad range and (ii) are not able to disentangle the role of less tangible forms of learning, such as social learning. The omission of the less tangible forms of learning may have important implications for the future penetration of technologies, energy transition, and energy systems in scenarios. A systematic analysis of a large sample of case studies, with a greater attention to the unfolding of short-run learning dynamics could yield robust general patterns that could be used by models. In turn, models such as IAMs could assess the sensitivity that learning dynamics have on energy and technology scenarios and could interpret the results in light of the insights provided by other disciplines such as IBL.

\subsection{Institutions}

As discussed in Section 2.2, quantitative system models represent institutions either implicitly or in an exogenous, ad-hoc manner. As a result, models are unable to generate insights into the institutional changes entailed by certain transitions that rely on broader systemic changes. In this section, we describe two different opportunities for enriching this component by (i) linking the applied economic literature and modelling and (ii) performing a comparative analysis of transition pathways.

\subsubsection{Linking the empirical literature and modelling}

The applied economic literature on the environment and institutions can offer empirical guidance by establishing quantitative patterns and stylized facts that can be used to improve models' representation of institutions. It examines relationships between institutions as described in Table 1 and indicators of policy adoption, policy effectiveness, and environmental outcomes quantitatively, relying on observed historical data. The literature provides empirical evidence on reduced-form relationships between decisions variables (e.g. R\&D investments and policy stringency; see Dasgupta et al., 2016), outcomes (e.g. energy intensity, green investments, emissions), and institutional contextual factors at the aggregate country level, which is the scale relevant to most models.

The most commonly used indicators are the Polity IV (Polity IV, 2011) indicators (democracy, autocracy, and polity), ${ }^{6}$ the World Governance Indicators (rule of law, voice and accountability, government effectiveness, and control of corruption), the Freedom House Index, and Corruption Perception Index from Transparency International ${ }^{7}$ (Transparency International (2015)). Normative and cognitive institutions as defined by Scott (1995) are difficult to measure and most of the environmental economics literature has focused on regulatory institutions or formal institutions (Joskow, 2008Kunčič, 2014). The main insights from this field of study are that institutions affect policy adoption

\footnotetext{
${ }^{6}$ Seen (2011)

7 See Dasgupta and De Cian (2018) for a detailed review of institutional indicators used in this literature.
} 
as well as their implementation and effectiveness (Dasgupta and De Cian, 2018). For example, democratic countries and open societies are generally associated with more participation into international environmental agreements and with better performance in terms of environmental indicators. Good governance encourages the adoption of environmental policies and generally leads to better environmental outcomes. Corruption can be a channel for environmental degradation, as it could lead to a sub-optimal use of resources and inefficiencies.

Institutional factors influence not only the ability to implement environmental policies, but also the type of policy chosen, policy stringency, as well as the effectiveness of the policy implemented. Models do not take these factors into account. Instead, they assume that environmental policies, once implemented, are equally effective across regions. The empirical evidence available in the current literature might not be suitable to be directly used in computational models, either because the empirical specification is not directly comparable to the equations used in the computational models or because the indicators used are not represented in the models. An example of tailoring empirical evidence for use in models is provided by Iyer et al. (2015), who use historical data to conclude that investment risks are higher in regions with inferior institutions. That empirical result was then used to differentiate investment risks across regions in an IAM to assess the implications for regional mitigation costs.

Future empirical research could explore the role of institutions in contexts that are more relevant for studies on low-carbon energy transitions. For example, IAM-based scenarios suggest strong absolute convergence in energy intensity across regions not only in the long-run but also in the short-run. However, empirical evidence does not necessarily support this assumption (Le Pen and Sevi, 2010). Instead, conditional convergence, i.e. countries tend to converge in energy intensity if they share common characteristics, seems more likely. Introducing more realism in the characterization of energy intensity convergence can improve the reliability of model-based assessments of climate policies. Comprehending the institutional factors that hinder convergence is also important to understand the complementary measures that need to be implemented in order to ensure policy effectiveness. Model-based scenarios assume strong convergence in energy intensity across regions, requiring improvement rates that for some regions (e.g. energy exporters) far exceed their historically observed rates. The question is why those regions have lagged behind in terms of energy efficiency. Is it reasonable to assume that those factors will disappear in the future? If not, what are the implications of considering the institutional barriers that have prevented energy intensity convergence also in future scenarios?

\subsubsection{Comparative analysis of transition pathways}

Transition pathways derived from MLP studies can be used not only to improve the characterization of actors and decision making in computational models (Section 3.1) but could also be used to enrich the characterization of the institutional dimension in general as described in Table 1. MLP approaches develop rich socio-technical scenarios, describing the change needed to make the quantitative, techno-economic oriented scenarios (Hof et al., 2018; Sluisveld et al., 2018) materialize (Geels et al., 2018). These socio-technical scenarios focus on societal and behavioral aspects such as types of actors, their goals, strategies, and resources (e.g. role of policy makers versus civil society) as well as institutional change (e.g. social and cultural changes to foster social acceptance of new technologies). Given the broad definition of institutions used in this paper, the transition narratives approach to enrich actor and decision-making representation in models using MLP insights, described in Section 3.1, also involves some degree of institutional changes (e.g. see definition provided in Table 1). Some of the interventions described in Table 5 are indeed regulatory changes (e.g. government support for car sharing in the MATISSE-KK model) and social and behavioral changes (e.g. preferences for technologies).

Neither the approach linking the empirical evidence and modelling, nor the comparative analysis of transition pathways would require major structural changes in quantitative system models, as they do not intend to achieve full integration. Thus, institution dynamics remain exogenous and mostly focused in current practices and power relations. Introducing endogenous dynamics of institutions more explicitly in the models used in transition scenarios would require deep structural changes in IAMs. Indeed, depicting both large energy systems and more complex social systems in the same model would imply extremely high computational requirements and extensive result evaluation processes. Schmitt (2014) developed a numerical IAM to analyze how endogenous political turnover between governments with heterogeneous preferences with respect to the level of greenhouse emissions affect climate change mitigation policies. The model builds on WITCH, but a number of simplifications were made to keep the problem computationally tractable. In other words, a richer and endogenous representation of institution dynamics comes at the expenses of realism with respect to the techno-economic components, which is the strength of quantitative models such as IAMs.

\section{Conclusions}

The increasing focus on implementation and transition dynamics towards long-term objectives requires a better understanding of what drives change and how those changes can be accelerated. Actors, decision-making, and institutions are important aspects for these drivers. Adopting greater realism with respect to these elements in low-carbon transition pathways is required to improve the understanding of transitions towards a low-carbon sustainable society. In this paper, we explored opportunities that arise from a deeper engagement of quantitative systems modelling with social science approaches such as sociotechnical transitions studies, initiative-based learning, and applied economics.

The explicit representation of actors and decision-making in models remains very limited. Limitations concerning (i) the lack of agent heterogeneity, (ii) weak empirical foundation for behavioral patterns and rules, (iii) stylized representations, (iv) decision mechanisms driven by techno-economic relationships and rational choice paradigms, and (v) the assumption of perfect knowledge in achieving the objective. The representation of institutions is stylized and only implicitly accounted for in quantitative systems modelling. Although actors, behaviors, and institutions are recognized to affect the emulated decision process in computational models, many of the socio-institutional factors remain highly stylized and are only captured through proxies.

The review carried out in Section 3 highlights several approaches for strengthening the representation of actors, decisions, and institutions in model-based scenario analysis (summarized in Table 6). Some opportunities rely on softer forms of integration and do not require major changes in the modelling infrastructure and therefore should have high priority. For example, with respect to actors and decision making, detailed transition narratives from socio-technical transition studies can be used to provide context to missing elements in quantitative systems modelling such as different configurations of actors. Actor heterogeneity could be increased by differentiating regional and demographic dimensions based on empirical data, such rural versus urban and income classes. A more demanding opportunity could entail model refinement in the form of improving actor heterogeneity to provide more explicit leads for assessing the influence of actors, behaviors, and institutional change by modelling actor behavior as internally dynamic and conditional to non-economic factors as in ABMs. Agent-based IAMs could in principle be developed, though perhaps higher priority should be given to first soft-linking ABMs and IAMs by exchanging their input and output, provided a common denominator among different models exist. Evidence on social learning from initiative-based learning case studies can be used to enrich the representation of learning dynamics in IAMs, though some significant effort needs to be carried out to gather robust evidence from a larger set of case studies. 
Table 6

Opportunities for enhancing actors and institutions in quantitative system models.

Source: Authors' compilation.

\begin{tabular}{|c|c|c|}
\hline Actors & $\begin{array}{l}\text { Ready to be implemented with existing modelling frameworks - lower } \\
\text { degree of integration across disciplines }\end{array}$ & $\begin{array}{l}\text { Need further model development - higher degree of } \\
\text { integration across disciplines }\end{array}$ \\
\hline Transition narratives & $\begin{array}{l}\text { Co-design transition narratives with insights from Multi-Level } \\
\text { Perspective studies }\end{array}$ & \\
\hline Increasing actor heterogeneity & Use empirical evidence to differentiate parameters across regions & $\begin{array}{l}\text { Carry out model refinement to improve actor } \\
\text { heterogeneity }\end{array}$ \\
\hline ABMs and IAMs & Soft-link ABMs and IAMs & Develop agent-based IAMs \\
\hline Initiative-based learning and modelling tools & Enrich learning dynamics in models & $\begin{array}{l}\text { Gather more robust evidence from initiative-based } \\
\text { learning case studies }\end{array}$ \\
\hline Institutions & $\begin{array}{l}\text { Ready to be implemented with existing modelling frameworks - Lower } \\
\text { degree of integration across disciplines }\end{array}$ & $\begin{array}{l}\text { Need further model development - Higher degree of } \\
\text { integration across disciplines }\end{array}$ \\
\hline $\begin{array}{l}\text { Linking the applied economic literature and } \\
\text { modelling }\end{array}$ & Link modelling tools with the applied economic literature & Introduce endogenous dynamics of institutions \\
\hline Comparative analysis of transition pathways & $\begin{array}{l}\text { Use transition narratives based on insights from Multi-Level } \\
\text { Perspective studies }\end{array}$ & \\
\hline
\end{tabular}

Regarding the opportunities to improve the representation of institutions, the applied economic literature already provides several examples of evidence that could be implemented in models through simplified reduced-form relationships. Introducing endogenous dynamics in institutional factors might increase the computational requirement of models significantly and potentially increase structural uncertainty.

The extent to which different analytical and modelling approaches across disciplines can be linked varies but it entails establishing common concepts, agreeing on a common problem frame that requires integration, identifying operational linkages, and agreement on parameters, metrics, indicators, and data. Integrating a much wider combination of real life aspects and dynamics into models leads to an increased complexity that would restrict them to smaller fields of applications (e.g. sectoral or country-level analysis). The respective weaknesses are inherent in their approaches and existing models are unable to cover all aspects of energy transition simultaneously. We believe that in the near future, a well-defined combination of models (e.g. soft-link) covering the same domain (e.g. electricity, heat) complemented by other social science approaches (e.g. comparative analysis of transition pathways and empirical evidence from the applied economic literature) could deliver new insights. Such an approach would also allow combining the strengths of the different approaches rather than trying to work around their respective weaknesses.

\section{Acknowledgement}

The research leading to these results has received funding from the European Union Seventh Framework Programme (FP7/2007-2013) under grant agreement no 603942 (PATHWAYS). MAEvS acknowledges the financial assistance from the European Union's Horizon 2020 Programme under grant agreement no 730053 (REINVENT).

\section{References}

Acemoglu, D., Robinson, J., 2010. The role of institutions in growth and development. Rev. Econ. Inst. 1 (2). https://doi.org/10.5202/rei.v1i2.14.

Acemoglu, D., Johnson, S., Robinson, J.A., 2005. Institutions as a fundamental cause of long-run growth. In: Handbook of Economic Growth. 1. pp. 385-472.

Clarke, L., et al., 2009. International climate policy architectures: overview of the EMF 22 International Scenarios. Energy Econ. 31, S64-S8.

Clarke, L., Jiang, K., Akimoto, K., Babiker, M., Blanford, G., Fisher-Vanden, K., Hourcade, J.-C., Krey, V., Kriegler, E., Löschel, A., McCollum, D., Paltsev, S., Rose, S., Shukla, P.R., Tavoni, M., van der Zwaan, B.C.C., van Vuuren, D.P., 2014. Assessing transformation pathways. In: Edenhofer, O., Pichs-Madruga, R., Sokona, Y., Farahani, E., Kadner, S., Seyboth, K., Adler, A., Baum, I., Brunner, S., Eickemeier, P., Kriemann, B., Savolainen, J., Schlömer, S., von Stechow, C., Zwickel, T., Minx, J.C. (Eds.), Climate Change 2014: Mitigation of Climate Change. Contribution of Working Group III to the Fifth Assessment Report of the Intergovernmental Panel on Climate Change. Cambridge University Press, Cambridge, United Kingdom and New York, NY, USA.

Dasgupta, S., De Cian, E., 2018. The influence of institutions, governance, and public opinion on the environment: Synthesized findings from applied econometrics studies. Energy Res. Soc. Sci. https://doi.org/10.1016/j.erss.2018.05.023.

Dasgupta, S., De Cian, E., Verdolini, E., 2016. The Political Economy of Energy Innovation'. 2016/17. UNU-WIDER, Helsinki.

Ekholm, T., Krey, V., Pachauri, S., Riahi, K., 2010. Determinants of household energy consumption in India. Energy Policy 38, 5696-5707.

Emmerling, J., Drouet, L., Reis, L.A., Bevione, M., Berger, L., Bosetti, V., Carrara, S., De Cian, E., De Maere D'Aertrycke, G., Longden, T., Malpede, M., Marangoni, G., Sferra, F., Tavoni, M., Witajewski-Baltvilks, J., Havlik, P., 2016. The WITCH 2016 Model Documentation and Implementation of the Shared Socioeconomic Pathways, Nota di Lavoro 42.2016. Fondazione Eni Enrico Mattei, Milan, Italy.

Eom, J., Clarke, L., Kim, S.H., Kyle, P., Patel, P., 2012. China's building energy demand: long-term implications from a detailed assessment. Energy 46, 405-419.

Epstein, J.M., Axtell, R.L., 1996. Growing Artificial Societies: Social Science from the Bottom Up. MIT/Brookings Institution.

Farmer, J.D., Hepburn, C., Mealy, P., Teytelboym, A., 2015. A third wave in the economics of climate change. Environ. Resour. Econ. 62, 329-357.

Geels, F.W., 2002. Technological transitions as evolutionary reconfiguration processes: a multi-level perspective and a case-study. Res. Policy 31, 1257-1274.

Geels, F.W., Schot, J., 2007. Typology of sociotechnical transition pathways. Res. Policy 36, 399-417.

Geels, F.W., Pfluger, B., McMeekin, A., 2018. From Global to National Scenarios: sociotechnical scenarios as a methodological tool to explore social and political feasibility in low-carbon transitions: bridging computer models and the multi-level perspective in UK electricity generation (2010-2050). In: Technological Forecasting and Social Change, Part of the Special Issue on "Understanding transition pathways. Insights from Bridging Modelling and Transition-science Based Studies".

Gupta, S., Tirpak, D.A., Burger, N., Gupta, J., Höhne, N., Boncheva, A.I., Kanoan, G.M., Kolstad, C., Kruger, J.A., Michaelowa, A., Murase, S., Pershing, J., Saijo, T., Sari, A., 2007. Policies, instruments and co-operative arrangements. In: Metz, B., Davidson, O.R., Bosch, P.R., Dave, R., Meyer, L.A. (Eds.), Climate Change 2007: Mitigation. Contribution of Working Group III to the Fourth Assessment Report of the Intergovernmental Panel on Climate Change. Cambridge University Press, Cambridge, United Kingdom and New York, NY, USA.

Hof, A.F., Carrara, S., De Cian, E., Oehler, P., Pfluger, B., van Sluisveld, M.A.E., van Vuuren, D.P., 2018. From global to national scenarios: bridging different models to explore power generation decarbonisation. In: Technological Forecasting and Social Change, Part of the Special Issue on "Understanding transition pathways. Insights from Bridging Modelling and Transition-science Based Studies".

Hofman, P., Boelie, S., Elzen, E., Geels, F.W., 2004. Sociotechnical scenarios as a new policy tool to explore system innovations: co-evolution of technology and society in the Netherland's electricity domain. Innov. Manag. Policy Pract. 6 (2), 344-360.

IPCC, 2007. In: Core Writing Team, Pachauri, R.K., Reisinger, A. (Eds.), Climate Change 2007: Synthesis Report. Contribution of Working Groups I, II and III to the Fourth Assessment Report of the Intergovernmental Panel on Climate Change. IPCC, Geneva, Switzerland (104 pp).

Iyer, G.C., Clarke, L.E., Edmonds, J.A., Flannery, B.P., Hultman, N.E., Mcjeon, H.C., Victor, D.G., 2015. Improved representation of investment decisions in assessments of CO2 mitigation. Nat. Clim. Chang. 5, 436-440. https://doi.org/10.1038/ NCLIMATE2553.

Joskow, P.L., 2008. Lessons learned from electricity market liberalization. In: Energy Journal, Vol. 29, Special Issue: The Future of Electricity: Papers in Honor of David Newbery.

Kaufman, D., Kraay, A., Mastruzzi, M., 2010. The worldwide governance indicators: methodology and analytical issues. In: World Bank Policy Research Working Paper 5430. World Bank, Washington, DC.

Köhler, J., 2006. Transport and the environment: the need for policy for long term radical change: a literature review for the DTI FORESIGHT project on Intelligent Infrastructure Systems. IEE Proc. Intell. Transp. Syst. 153 (4), 292-301.

Köhler, J., Whitmarsh, L., Nykvist, B., Schilperoord, M., Bergman, N., Haxeltine, A., 2009. A transitions model for sustainable mobility. Ecol. Econ. 68, 2985-2995. 
Köhler, J., Turnheim, B., Hodson, M., 2018. Low Carbon Transitions Pathways in Mobility: Applying the MLP in a Combined Case Study and Simulation Bridging Analysis of Passenger Transport in the Netherlands. https://doi.org/10.1016/j. techfore.2018.06.003.

Krey, Volker, 2014. Global energy-climate scenarios and models: a review. WIREs Energy Environ. https://doi.org/10.1002/wene.98.

Krey, V., O'Neill, B.C., van Ruijven, B., Chaturvedi, V., Daioglou, V., Eom, J., Jiang, L., Nagai, Y., Pachauri, S., 2012. Urban and rural energy use and carbon dioxide emis sions in Asia. Energy Econ. 34, S272-S283.

Kriegler, E., et al., 2013a. What does the $2^{\circ} \mathrm{C}$ target imply for a global climate agreement in 2020? The LIMITS study on Durban platform scenarios. Clim. Chang. Econ. 4, 1340008.

Kriegler, E., Tavoni, M., Riahi, K., van Vuuren, D.P., 2013b. Introducing the LIMITS special issue. Clim. Chang. Econ. 4, 1302002.

Kriegler, E., et al., 2014. A new scenario framework for climate change research: the concept of shared policy assumptions. Clim. Chang. 122, 401-414.

Kriegler, E., et al., 2015. Making or breaking climate targets: the AMPERE study on staged accession scenarios for climate policy. Technol. Forecast. Soc. Chang. 90, 24-44. https://doi.org/10.1016/j.techfore.2013.09.021.

Kunčič, A., 2014. Institutional quality dataset. J. Inst. Econ. 10 (1), 135-161. https://doi. org $/ 10.1017 /$ S1744137413000192.

Le Pen, Y., Sevi, B., 2010. On the non-convergence of energy intensities: evidence from a pair-wise econometric approach. Ecol. Econ. 69 (3), 641-650.

Li, F.G.N., 2017. Actors behaving badly: exploring the modelling of non-optimal behaviour in energy transitions. Energ. Strat. Rev. 15, 57-71.

Markard, J., Raven, R., Truffer, B., 2012. Sustainability transitions: an emerging field of research and its prospects. Res. Policy 41, 955-967.

McCollum, D.L., et al., 2017. Improving the behavioral realism of global integrated assessment models: an application to consumers' vehicle choices. Transp. Res. Part D: Transp. Environ. 55, 322-342.

Melnikov, N.B., O'Neill, B.C., Dalton, M.G., 2012. Accounting for household heterogeneity in general equilibrium economic growth models. Energy Econ. 34, 1475-1483.

Melnikov, N.B., O'Neill, B.C., Dalton, M.G., van Ruijven, B.J., 2017. Downscaling heterogeneous household outcomes in dynamic CGE models for energy-economic analysis. Energy Econ. 65, 87-97.

Mundaca, L., Neij, L., Worrell, E., McNeil, M., 2010. Evaluating energy efficiency policies with energy-economy models. Annu. Rev. Environ. Resour. 35 (1), 305-344.

Nakicenovic, N., Alcamo, J., Davis, G., de Vries, B., Fenhann, J., Gaffin, S., Gregory, K., Grübler, A., Jung, T.Y., Kram, T., Emilio la Rovere, E., Michaelis, L., Mori, S., Morita, T., Pepper, W., Pitcher, H., Price, L., Riahi, K., Roehrl, A., Rogner, H., Sankovski, A., Schlesinger, M., Shukla, P., Smith, S., Swart, R., van Rooyen, S., Victor, N., Dadi, Z., 2000. IPCC Special Reports: Special Report on Emissions Scenarios. Cambridge University Press, Cambridge, UK.

Nakicenovic, N., et al., 2003. IPCC SRES revisited: a response. Energy Environ. 14 (2\&3), $187-214$

O'Neill, B.C., Dalton, M., Fuchs, R., Jiang, L., Pachauri, S., Zigova, K., 2010. Global demographic trends and future carbon emissions. PNAS 107 (41), 17521-17526. https://doi.org/10.1073/pnas.1004581107.

O'Neill, B.C., Ren, X., Jiang, L., Dalton, M., 2012. The effect of urbanization on energy use in India and China in the iPETS model. Energy Econ. 34, S339-S345.

O'Neill, B.C., Kriegler, E., Riahi, K., Ebi, K.L., Hallegatte, S., Carter, T.R., Mathur, R., van Vuuren, D.P., 2014. A new scenario framework for climate change research: the concept of shared socioeconomic pathways. Clim. Chang. 122, 387-400.

O'Neill, B.C., et al., 2015. The roads ahead: narratives for shared socioeconomic pathways describing world futures in the 21st century. Glob. Environ. Chang. https://doi.org/ 10.1016/j.gloenvcha.2015.01.004.

Polity IV, 2011. Polity IV Project: Political Regime Characteristics and Transitions, 1800-2010. www.systemicpeace.org/polity/polity4.htm.

Riahi, K., et al., 2015. Locked into Copenhagen pledges - implications of short-term emission targets for the cost and feasibility of long-term climate goals. Technol. Forecast. Soc. Change 90, 8-23.

Schmitt, A., 2014. Beyond Pigou: Climate change mitigation, policy making and distortions (Doctoral Dissertation). Department of Economics, Stockholm University.

Scott, W.R., 1995. Institutions and Organizations: Ideas, Interests, and Identities, 4th edition. 2013. Sage Publications, Thousand Oaks, CA, pp. 56.

Shelley, M., 2012. The emergence of new cultures of mobility: stability, openings and prospects. In: Geels, F.W., Kemp, R., Dudley, G., Lyons, G. (Eds.), Automobility in Transition? Routledge, Abingdon and New York, pp. 180-202.

Staub-Kaminski, I., Zimmer, A., Jakob, M., Marschinski, R., 2013. Climate policy in practice: a typology of obstacles and implications for integrated assessment modelling. Clim. Chang. Econ. 5 (1).

Stehfest, E., van Vuuren, D.P., et al., 2014. Policy applications Integrated Assessment of Global Environmental Change with IMAGE 3.0 - Model Description and Policy Applications.

Tavoni, M., et al., 2013. The distribution of the major economies' effort in the Durban platform scenarios. Clim. Chang. Econ. 4, 1340009.

Transparency International, 2015. Corruption Perceptions Index 2015. Available online at. http://www.transparency.org/cpi2015\#results-table.

Turnheim, B., et al., 2015. Evaluating sustainability transitions pathways: bridging analytical approaches to address governance challenges. Glob. Environ. Chang. 35, 239-253. https://doi.org/10.1016/j.gloenvcha.2015.08.010.

UNFCCC, 2015. The Paris Agreement. Conference of the Parties Twenty-first Session Paris, 30 November to 11 December 2015. http://unfccc.int/resource/docs/2015/ cop21/eng/10a01.pdf.

van Ruijven, B.J., et al., 2011. Model projections for household energy use in India. Energy Policy 39, 7747-7761.

van Sluisveld, M.A.E., Martínez, S.H., et al., 2016. Exploring the implications of lifestyle change in $2{ }^{\circ} \mathrm{C}$ mitigation scenarios using the IMAGE integrated assessment model.
Technol. Forecast. Soc. Chang. 102, 309-319.

van Sluisveld, M.A.E., Hof, A.F., Carrara, S., Geels, F.W., Nilsson, M., Rogge, K., Turnheim, B., van Vuuren, D.P., 2018. Aligning integrated assessment modelling with socio-technical transition insights: An application to low-carbon energy scenario analysis in Europe. Technol. Forecast. Soc. Chang. https://doi.org/10.1016/j. techfore.2017.10.024. (ISSN 0040-1625).

van Vuuren, D.P., Kok, M. (Eds.), 2012. Roads from Rio + 20 Pathways to Achieve Global Sustainability Goals by 2050. PBL Netherlands Environmental Assessment Agency: Bilthoven, The Netherlands.

Victor, D., 2015. Climate change: embed the social sciences in climate policy. Nature 520, 27-29.

Voinov, A., Bousquet, F., 2010. Modelling with stakeholders. Environ. Model Softw. 25, 1268-1281.

Voinov, A., Seppelt, R., Reis, S., Nabel, J.E.M.S., Shokravi, S., 2014. Values in socioenvironmental modelling: persuasion for action or excuse for inaction. Environ. Model Softw. 53, 207-212.

Wilson, C., Pettifor, H., McCollum, D., 2014. Improving the Behavioral Realism of Integrated Assessment Models of Global Climate Change Mitigation: A Research Agenda. ADVANCE Project Deliverable No. 3.2. Tyndall Centre for Climate Change Research, Norwich, UK and International Institute for Applied Systems Analysis (IIASA), Laxenburg, Austria.

Wilson, C., Pettifor, H., Cassar, E., Kerr, L., Wilson, M., 2018. Energy Efficiency. pp. 1-18. https://doi.org/10.1007/s12053-018-9679-8.

Enrica De Cian is Associate Professor in Environmental Economics at Ca' Foscari University of Venice and a Senior Researcher at Fondazione CMCC. She is an ERC grantee with a project focusing on energy use for adaptation (ENERGYA) through the use of energy across different sectors of the economy (residential, industry, commercial, agriculture). Since 2016 she has been in charge of coordinating interdisciplinary research activity at CMCC aimed at developing a harmonized, gridded database merging climate, environmental, and economic data. Her research has gained recognition in the state-ofthe-art literature leading to more than 30 publications in peer-reviewed journals. Her research focuses on induced innovation and technological change, integrated assessment modeling, climate change impacts and adaptation.

Shouro Dasgupta is currently a Research Fellow at Università Ca' Foscari Venezia and a Researcher at CMCC. His major research involves econometric analysis of the impact of climate change on economic activity, human health, and the labor force. He is currently involved in the $\mathrm{COACCH}$ project, investigating the impact of climate change on labor productivity/supply and energy consumption/supply and using spatial econometric techniques to investigate the impact of climate change using high-resolution data. Shouro has recently been involved in PATHWAYS - an FP7 project, analyzing the role of governance and institutions on environmental performance and innovation. Shouro holds a $\mathrm{PhD}$ in Science and Management of Climate Change from the Ca' Foscari University of Venice (dissertation on the impacts of climate change) and an MA in Economics from the University of New Hampshire.

Mariësse A.E. van Sluisveld is a researcher at PBL Netherlands Environmental Assessment Agency and Utrecht University, the Netherlands. She holds a PhD from Utrecht University. Her current work focuses on alternative transition pathways to meeting long-term climate policy targets.

Andries F. Hof is senior researcher at PBL Netherlands Environmental Assessment Agency and guest researcher at the Faculty of Geosciences, Utrecht University. He holds a university degree in economics (1999), after which he conducted research at several institutes in the Netherlands, Germany, and the US. In 2007, he started working on a EU research project about mitigation and adaptation strategies for climate change policy at $\mathrm{PBL}$ and received his $\mathrm{PhD}$ with this topic in 2010. Andries has authored more than 40 publications in peer-reviewed journals.

Detlef P. van Vuuren is professor of integrated assessment of global environmental change at Utrecht University, the Netherlands, and senior researcher at PBL Netherlands Environmental Assessment Agency. His work concentrates on scenario analysis of response strategies to global environmental change issues. Detlef van Vuuren has published over 240 peer-reviewed articles and has been an author on a large number of integrated assessment reports.

Jonathan Köhler is Senior Scientist at the Fraunhofer ISI (Institute for Systems and Innovation research). He works in transport economics and is an expert on innovation theory and long run technological change, macroeconomics and system dynamics. He has worked on biofuels in the transport sector and sustainable innovation in the transport sector. He is now working on transitions modelling and the modelling of innovation systems and processes in transport. He has developed the MATISSE-KK agent-based model (ABM) of transitions in transport and the CLEANSHIP ABM of technology investment and development in shipbuilding. He is member of the steering committee of the Sustainability Transitions Research Network (STRN), responsible for modelling issues.

Benjamin Pfluger studied Industrial Engineering at the University of Karlsruhe. Dissertation "An agent-based approach on simulating the impacts of importing renewable energy from North Africa into the Italian electricity market". Since September 2008, research assistant at the Fraunhofer Institute for Systems and Innovation Research ISI in Karlsruhe; until December 2011 in the Competence Center Energy Policy and Energy Systems, since January 2012 in the Competence Center Energy Policy and Energy Markets. 